\title{
Current Trends in Childhood Obesity Research
}

\author{
Leah Frerichs • Douglas M. Puricelli Perin • \\ Terry T.-K. Huang
}

Published online: 23 August 2012

(C) Springer Science+Business Media, LLC 2012

\begin{abstract}
Childhood obesity is a global health issue. To identify research trends and gaps of childhood obesity research, we reviewed MEDLINE publications from January 2011 to May 2012 and qualitatively analyzed the major domains and themes of research focus. Major domains are: measurements, obesity correlates, prevention interventions, treatment interventions, and policy issues. Key advances and innovations are highlighted within each domain. Emerging areas include the advancement of measurement methodologies that simultaneously capture individual and contextual information across time, analysis of policy problems, and the development of multilevel, community interventions. However, few effective and sustainable interventions are exemplified; some strategies are promising. Recommendations for future research includes the adoption of a systems approach that integrates individual, environmental, and policy change, the scale up and diffusion of innovations, studies of intended and unintended policy impacts, and the design and testing of effective social marketing strategies.
\end{abstract}

Keywords Childhood obesity · Children · Overweight . Diet $\cdot$ Physical activity $\cdot$ Prevention

\section{Introduction}

Childhood obesity remains persistent in developed countries and continues to increase in developing countries despite

L. Frerichs $•$ D. M. P. Perin • T. T.-K. Huang

University of Nebraska Medical Center College of Public Health, Omaha, USA

T. T.-K. Huang $(\bowtie)$

Department of Health Promotion, Social and Behavioral Health, College of Public Health, University of Nebraska Medical Center, 984365 Nebraska Medical Center,

Omaha, NE 68198-4365, USA

e-mail: tthuang@unmc.edu increases in public health research and intervention in the past three decades [1]. In the United States, the rise in childhood obesity began in the early 1980s and tripled in prevalence by 2000 [2]. Recent epidemiologic studies reveal a stabilizing, although persistent, trend in the rate of overweight and obesity in children and adolescents [3, 4]; however, differences between socioeconomic and racial/ethnic groups indicate growing disparities [5]. Moreover, the prevalence of overweight children is spreading worldwide and poses significant risk to public health and economic security [6]. The prevalence of overweight and obese children is greater than $20 \%$ in many countries outside the United States, such as the United Kingdom, Australia, Chile, and Mexico [7]. Fast-developing Asian countries, such as India and Thailand, also are reporting rapidly increasing prevalence of overweight children, at $30 \%$ and $15 \%$, respectively [8].

The focus of research on childhood obesity has shifted during the past three decades. Research began with mostly medical studies documenting the natural history and physiological sequelae of obesity, followed by individual- and family-based interventions, and, more recently, environmental correlates of and policy approaches to childhood obesity. Although much has been learned about the nature of childhood obesity, the problem remains exceedingly difficult to prevent and treat. By and large, although intensive familybased interventions can be efficacious over the short term, the effect of individual-level approaches alone, including education and skill-based techniques, are difficult to sustain [9]. In recognition of the need for greater and more sustained population-level impact, recent efforts began to identify attributes of the built environment in relation to diet and physical activity as well as to debate the merit of policy interventions, such as menu labeling mandates or soda taxation, to incentivize healthy behaviors and disincentivize unhealthy ones [10].

The purpose of this review is to provide a critical analysis of the state of the science in population-based childhood 
obesity research. The goal is to summarize papers published since the beginning of 2011 to provide a snapshot of current research and identify innovations, emerging areas, and gaps in the area of childhood obesity. This is not meant to be an exhaustive review. Rather, we hope to provide readers an overview of what is being done and what can be expected in the near future, from our perspective. This review should inform researchers, policymakers, as well as the public regarding the direction of childhood obesity research as a field.

\section{Methods}

To identify the most recent findings, a literature search of MEDLINE publications from January 2011 through May 2012 using terms of "childhood obesity" OR ("children" AND "physical activity, exercise, nutrition, diet or food") was conducted. We excluded studies unrelated to childhood obesity, basic science studies, studies of physical activity or nutrition interventions with targets not specific to childhood obesity (e.g., youth behavioral problems), descriptive studies of obesity prevalence and trends, studies on consequences of childhood obesity, and studies of childhood obesity in specialized populations (e.g., childhood cancer survivors). Review and perspective papers, although not counted in the literature search, were examined for their potential insight to guide future directions in research.

In total, 10,354 publications were identified. Upon excluding studies deemed outside the scope of this review, 936 papers were retained for analysis. Publications were categorized into major domains and were reviewed to identify subcategories or themes. We employed five core domains to sort the publications: measurement studies; obesity correlates; prevention interventions; treatment interventions; and policy issues.

This paper qualitatively summarizes the major themes identified and highlights selected publications of innovation within each domain. In addition, we offer an editorial discussion of childhood obesity research trends, gaps, and recommendations.

\section{Results}

Figure 1 illustrates findings from the overall thematic analysis of the publications included in this review, indicating the relative proportion of each domain and major themes within it. Studies on correlates of obesity represented almost half of the publications abstracted. A quarter of the publications fell under the prevention intervention domain. Measurement studies, treatment interventions, and studies on policy issues each represented $<10 \%$ of the publications. We briefly describe the themes identified within each domain and highlight the innovative studies by domain, as follows.

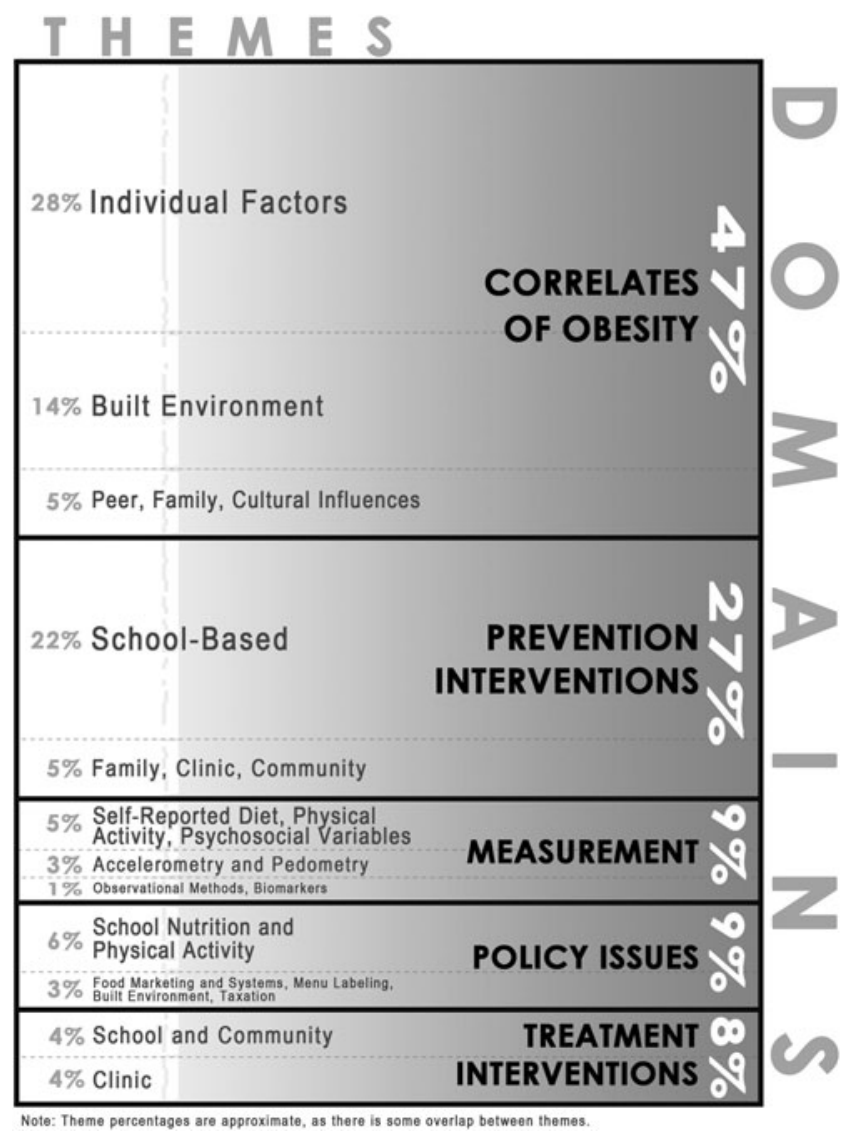

Fig. 1 Distribution of childhood obesity research papers by domain and theme from MEDLINE, January 2011-May 2012. Publications on basic science research, obesity prevalence and consequences, populations with special health conditions, and non-obesity-related diet and physical activity are excluded

\section{Measurement Studies}

Eighty publications related to methods of measuring physical activity, diet, or overweight and obesity. Development or validation of tools to measure dietary and physical activity behaviors, along with psychosocial instruments, dominated this domain.

Several publications focused on the development of electronic systems for self-reported dietary intake. Through formative evaluation (e.g., focus groups with children), several countries developed extensive databases of food items, images, and automated prompts that guide children or their parents in the recall of foods and portion sizes consumed. FIRSSt4 (United States) [11], Web-DASC (Denmark) [12], and EPIC-Soft (trans-Europe) [13, 14] each showed promising results in terms of feasibility and usability; however, further testing to establish validity and reliability is needed.

Of note, validation of accelerometry was performed in preschool ages, whereas prior research had mostly been in older children and adults. Van Cauwenberghe et al. [15] found accelerometry correlated with intensity levels 
measured with the Observational System for Recording Physical Activity in Children ( $\mathrm{r}=0.66)$ for toddlers. Davies et al. [16] identified acceptable sensitivity and specificity levels of the ActivPAL ( $86.7 \%$ to $97.3 \%$ ) to predict toddler postures (e.g., sit, stand, crawl) compared with videorecorded movements. In the pursuit of simpler measurement tools, pedometers were compared with accelerometry in several studies of school-age children to determine stepcount cut-points that correlated with levels of activity intensity [17-20].

Advances were made in technology to capture real-time physical activity and contextual information simultaneously. Oreskovic et al. [21••] furthered the methodology to combine accelerometry and global positioning system (GPS) by testing several data collection methods that revealed patterns of activity mapped with location information across time. Dunton et al. [22••] validated the use of ecological momentary assessment (EMA) - mobile phone surveys for capturing real-time physical activity and context - with accelerometry and found a 4-day protocol with three to seven surveys per day yielded valid physical activity levels. Technological advances in measuring habitual diet were few; however, one study enhanced a digital photo-analysis method with clear participant instructions, which improved the data quality and resulted in correlations with $24-\mathrm{hr}$ recalls ranging from 0.62 to 0.78 across major food groups [23].

\section{Correlates of Obesity}

Studies on the associations and perceptions of risk or protective factors with obesity constituted the largest domain (443 publications). This domain included studies on individual, social, and environmental influences, such as dietary and physical activity patterns, parental factors, and factors in the built environment.

Four twin and sibling studies attempted to disentangle the role of genetics and environment on weight status. Brown and Roberts [24] found that, among adolescents, timeconstant factors (i.e., genetics, individual characteristics, home environments) and time-changing factors (i.e., social network influences) explained $43 \%$ and $44 \%$, respectively, of weight correlations across statistical models. Among adult-sibling models, the contribution of time-constant factors remained relatively high (33-38 \%), but time-changing factors explained less variation (5-15\%). Dubois et al. [25] showed that a common environment explained $74-87 \%$ of variation in body height, weight, and body mass index (BMI) among twins at early ages, but the variance explained was markedly reduced to less than $20 \%$ by age 19 years. These studies point to the importance of targeting family and social environments in early childhood.

Evidence on the influence of home and built environments has strengthened with recent research. Three studies on exposure to green space found positive correlations with moderate to vigorous physical activity (MVPA) [26-28]. For example, Almanza et al. [26] found children with $>20$ minutes of daily exposure to greener spaces engaged in nearly five times the daily rate of MVPA than those with nearly zero daily exposure. In addition, there have been some controversial findings on the role of the built environment. One study in Canada found children in the highest quartile of street connectivity were less likely to be physically active than those in lower quartiles, opposite previously observed positive associations in adult populations [29].

An emerging area of innovation is the increasing awareness of correlates of obesity overlapping with those of environmental sustainability. For example, Stevens and Brown [30••] found that children living in Leadership in Energy and Environmental Design-Neighborhood Development communities had higher levels of moderate physical activity than those in mixed and less walkable communities. Another study showed that children who moved to smartgrowth communities did not increase their overall activity level, but the location and context of physical activity changed [31].

Multilevel studies that captured the context in which behavior takes place revealed more depth to understand the individual and contextual interdependence. Dunton et al. [32] described physical activity patterns in relation to both location and social context (i.e., number of family and/ or friends nearby). Beets et al. [33] found that children were most physically active with other children of their same age in outdoor settings by using a photovoice methodology.

\section{Prevention Interventions}

Prevention interventions comprised of 253 publications. Within this domain, school-based interventions targeting elementary ages were the most common, followed by interventions focused on the home environment. Several clinical intervention studies tested specific hypotheses, including methods to improve taste preferences for healthy foods or reduce portion sizes, motivate increased physical activity, and influence perceptions about food and activity via media.

School-based prevention interventions used diverse strategies, such as teacher or specialist-led curricula, peermodeling, changes to the school cafeteria, and family outreach. Environmental strategies often focused on the school cafeteria but also included active school transportation and changes to the recess environment. Two publications described innovative educational programs. Jones et al. [34••] described a multicomponent program that integrated food sustainability with healthy eating and found increased self-reported fruit and vegetable consumption as well as changes to cafeteria procurement and preparation practices. Another study focused on a youth-advocacy approach that 
assisted elementary youth to advocate for policy or environmental change [35]. The youth chose activities, such as obtaining a fruit and vegetable snack stand and requesting smaller portioned bottles in a milk vending machine. Evaluation showed a significant decrease in percent energy from fat and increase in fruit servings among intervention school participants compared to those in control schools.

Home-based interventions were common, but, unlike previous studies, many recent studies focused on families with preschool age children. Several publications described interventions targeting mothers and families during and/or immediately following pregnancy. Most of these studies were too new to produce information on outcomes; however, one study with the primary intent to improve mother's post-pregnancy weight loss while her newborn was between 2 to 10 months found that children had slower weight gain between 2 to 4 years when mothers received lifestyle counseling on diet and exercise [36].

Programs targeting the preschool age group within childcare also were reported. Eight publications reported primary outcomes, of which all indicated significantly positive effects on physical activity and/or diet, but findings regarding BMI were mixed: two found decreases [37, 38], two found no impact $[39,40]$, and the remaining did not report anthropometric outcomes [41-44]. For example, the Romp \& Chomp intervention in Australia included health education combined with changes to family day care environments and found a decrease in screen time and increase in active play but did not report anthropometric outcomes [41]. The Hip-Hop to Health program in Chicago involved classroom-based education, integrated instructional activities on exercise, and family outreach [39]. Compared with controls, intervention participants showed an increase of $7.46 \mathrm{~min} /$ day of MVPA and a $27.8 \mathrm{~min} /$ day decrease in screen time; however, there was no significant impact on BMI.

Few interventions were multilevel and community-based. One large-scale intervention focused on capacity-building and grassroots activities to promote healthy behaviors through social marketing and educational strategies in the Pacific (Australia, New Zealand, Fiji, and Tonga), using a community-based participatory approach [45]. Specific communities within this intervention reported limited results. For example, Tonga's evaluation indicated increases in obesity and overweight prevalence in both intervention and control communities, and no significant impact on behavior [46]. Nevertheless, the study indicates that community readiness, infrastructure, and capacity building are critical to community-level change [45].

Another study described an innovative multilevel intervention that targeted interactions between levels of the food system by simultaneously working with food producers, distributors and consumers [47]. The intervention included activities to advocate to food producers for increased supply of healthy foods at reduced prices, to assist distributors to improve marketing and promotion of healthy items using strategies, such as shelf-labeling, and to increase consumer demand through educational and social marketing outreach with activities, such as healthy cooking demonstrations. Outcomes were not reported, but the study found acceptable fidelity to planned intervention components (e.g., store shelf labels displayed correctly approximately $60-100 \%$ of the time).

The EPODE program (Ensemble prévenons l'obésité des enfants or Together let's prevent childhood obesity) provides an example of effective social marketing at both central and local levels [48••]. EPODE began with ten French pilot communities in 2004 and has since expanded to more than 500 communities worldwide. Other interventions in the European Union and Italy similarly described centralized efforts to develop and support community-based programs that influence individual, social, and environmental contexts $[49,50]$. Lastly, the Basic Law on Shokuiku was enacted in 2005 in Japan, which resulted in the subsequent establishment of a school-based program that uses a multilevel approach to support improved food culture, environments, and individual knowledge [51].

Most clinical interventions presented experimental strategies on how to improve some aspect of diet, such as reducing food portion sizes or nudging youngsters into selecting healthy foods. Harnack et al. [52] found that preschool children who served themselves, compared with children who received portioned meals from childcare providers, ate significantly more servings of fruits and vegetables, fewer servings of meat, and lower percent energy intake from fat. In another study, adolescent participants using a special plate designed by their peers selected less food overall and more fruits than those using a standard plate, and participants with higher BMIs selected a greater amount of healthful food when using the special plate [53]. Reicks et al. [54] found that, with the addition of green bean and carrot photos in food tray compartments, twice as many students selected green beans ( $14.8 \%$ vs. $6.3 \%$ ) and three times as many selected carrots ( $36.8 \%$ vs. $11.6 \%)$.

Clinical interventions also assessed the impact of food advertising and media on dietary behavior. One study revealed neophobia impacted children's responsiveness to food advertisements [55]. Following exposure to healthy food advertisements, neither children with high nor low neophobia increased their consumption of healthy food items, but low-neophobic children decreased their consumption of chocolate, whereas high-neophobic children increased their consumption, potentially explaining why increased energy intake following healthy food advertisements had been observed [55].

Lastly, among clinical interventions on physical activity, one study found that especially among girls, the 
combination of activity choice with mastery increased total physical activity time compared with low-choice and/or low-mastery intervention modalities [56]. Several studies reported on the impact of "active" video games, but the findings were mixed. Two studies reported increased physical activity levels among active video game users compared with traditional video game users and participants in a traditional physical education class [57, 58]. Conversely, neither Baranowski et al. [59] nor Owens et al. [60] found evidence that active video games increased overall physical activity among children compared with controls.

\section{Treatment Interventions}

There were 75 publications on treatment interventions. The majority of treatment interventions centered largely on individual- or group-based lifestyle counseling. Familybased interventions on parenting skills, conflict resolution, and problem solving were common. One notable clinical trial tested unique counseling strategies to assist children with appetite awareness and identifying cues and exposures to reduce eating in the absence of hunger. The study found participants in the cue-exposure group reduced their intake significantly and maintained reductions at 6 months [61].

Four studies tested specific dietary strategies, such as meal replacements or low-fructose diet [62-64]. The diets reduced BMI; however, diminishing impact and long-term maintenance were concerns. Similar to prevention interventions, active video games also were tested as a treatment strategy; the effect was more favorable as a treatment modality. For example, two studies found significant treatment effects on BMI (reductions of -0.24 and -0.48 compared with controls), and one noted a reduction in percent body fat $(-0.83 \%)$ at 24 weeks $[65,66]$. Another intervention utilized a short message service via mobile phones to provide overweight and obese children with personalized feedback and prompts to encourage healthy behaviors [67]. This study did not result in BMI reduction; however, the intervention group had a lower dropout rate and children with the greatest weight loss engaged more actively with the message service [68]. Finally, as part of the protocol of a randomized controlled trial in 3- to 10-year-old children, one paper showcased a technology under development to integrate treatment across settings [69]. ETIOBE (e-therapy for obese children) is a comprehensive package of electronic monitoring systems that provide integrated platforms to allow data linkage and transfer for the clinician and the participant in personal computer and mobile device formats [70].

\section{Policy Issues}

Eighty-five publications explored policy issues including policy impacts on nutrition and physical activity, the quality and content of obesity prevention policies, and factors related to the process of policy implementation. School policies, food marketing, menu labeling, and policies on the built environment have particularly been the focus of attention in recent years.

The majority of publications reviewed focused on schoolrelated physical activity and nutrition policies. Boles et al. [71] showed that schools in a U.S. state with formal nutrition and physical activity guidelines had significantly improved policies, such as less physical education exemptions and more restrictions on competitive food sales, compared with states without such guidelines. In the United Kingdom, Haroun et al. [72] found that changes to school policy were associated with improved nutritional profiles of student food selections. Bocarro et al. [73*0] explored the impact of school sports policy and found that the interaction of policy and setting (i.e., sport-specific, multi-purpose, open area) significantly increased activity levels of boys but not girls, suggesting that policy mandates for environmental change would be just as important as for physical education requirements.

In the food-marketing area, studies indicated that food advertisements disproportionately represented unhealthy foods [74-78], and numbers of unhealthy advertisements increased during peak child viewing times [74, 79, 80]. Several studies also focused on the themes and discourse within food marketing and found common use of emotional appeals to increase food cravings and portraying food as a mood enhancer [81-83]. Similar appeals were found in two studies that analyzed food packaging, as well as the predominant use of promotional characters $[84,85]$. One publication provided a critical analysis of an "advergaming" website for breakfast cereals and found that nutrition information was undermined by marketing content. The website discussed the importance of nutritional balance and caloric moderation but included "advergames" with spokes characters that have endless appetites and can eat virtual boxes of cereal in a single bite $[86 \bullet \bullet]$.

On gaps and weaknesses of current marketing policies, Jones et al. [87] reported that despite the Australian Association of National Advertisers Codes of Practice, which aim to improve self-regulation of unhealthy food advertising, magazines still included branded unhealthy food references and the boundaries between advertising, product placement, and editorial content often were blurred. Similarly, a Canadian study found self-regulation of advertising has not significantly impacted television food advertising in Quebec or Ontario, particularly among English-language advertisements [88].

Relatively few studies focused on menu labeling or taxation policies. One study found 15 of 22 chain restaurants in London did not provide portion size or nutrition information [89], and one U.S. study indicated that menu labeling increased parental awareness of nutrition information but did 
not significantly decrease the actual percentage of calories purchased for their children [90]. Cigarette taxes were significantly associated with an increase in BMI but not obesity among children with mothers who smoked [91]. In Sweden, Nordstrom and Thunstrom [92••] simulated the impact of potential tax reforms with the intent to increase fiber intake on food consumption across different household categories and found that among seniors and families without children, reforms would lead to increases in fiber with concurrent increases in added sugar and fat intake; however, among families with children, the reforms would lead to small increases in fiber with concurrent reductions in the unhealthy nutrients. Finally, von Tigerstrom et al. [93] provided an analysis of major tax reforms in Canada to improve physical activity, including income tax exemptions for organized sports and sales tax reductions on items, such as children's bicycles and footwear. The authors noted that major weaknesses included delayed benefits from income tax incentives and unintended increases of sales tax on other items.

With the exception of two studies that found increased physical activity following renovations to community parks [94, 95], studies on the impact of built environment policies did not assess behavior or obesity outcomes. Notable papers included a legal analysis of federal, state, and local policies that impact park and recreational settings, including the interplay of direct park establishment, tax and funding implications, and coordinating roles across all levels that results in challenges for targeted policy change [96]. Lee discussed multisector partnerships and complementary roles integral to the implementation of the Active Design Guidelines in New York City, which constitute an innovative set of architectural design features for buildings, streets, and urban spaces that can enhance physical activity [97••]. Health partners hosted forums to innovate and conceive strategies, architectural and city partners helped to determine feasibility, and researchers designed evaluations to build an evidence base.

Regarding policy implementation, Aarts et al. [98] used a multiround Delphi process to identify policies considered most feasible across sectors (i.e., public health, sports, youth and education, spatial planning/public space, traffic and transportation and safety). Policies with high levels of cultural and community acceptability, as well as political and financial feasibility, were most favorable across sectors. In the same project, it also was reported that increasing awareness of policy effectiveness and positively perceived political context facilitated multisectoral policy action [99]. Olstad et al. [100] similarly identified the importance of intersectoral linkages and communication to enhance the implementation of nutritional guidelines across childcare, school, and recreation settings.

Research also highlighted the perceptions of policies and factors that affect policy implementation and compliance.
For example, Lanier et al. [101] found that teachers were often unaware of their respective school's wellness policies, and two studies identified the school principals' leadership as key to improved physical activity and nutrition policy implementation $[102,103]$. One study identified that lower complexity, higher compatibility, and greater perceived relative advantage assisted schools in implementing nutrition guidelines [104]. In another example, Andreyeva et al. [105••] assessed food retailers' attitudes and perceptions regarding healthy food provision. Food retailers noted that stocking decisions were driven by customer demand, which they perceived as low for healthy food items. Furthermore, this study revealed that food producer and supplier networks varied across stores, but the least healthy foods were most likely to be direct-store delivery providing convenient direct shelving of products, whereas healthier foods were more likely to be self-supply or general delivery.

\section{Trends, Gaps, and Recommendations}

Despite accelerated attention on childhood obesity in recent years [108, 109], the number of innovative prevention and treatment interventions remains small, relative to descriptive and mechanistic studies of factors that correlate with obesity, suggesting both a gap in the generation and testing of novel solutions as well as a delay in the research community's response to social calls to action. In recent times, both the National Institutes of Health and the Institute of Medicine in the United States have called for the adoption of a systems approach to childhood obesity [108-111]. A systems approach calls for intervening across and in-between multiple levels of the complex system of childhood obesity, so that individuals and the environment are simultaneously activated for change [112]. Based on our scan of the literature, however, operationalization of the systems approach remains scant and should guide the next generation of obesity interventions. Increasingly, efforts are beginning to target earlier stages in the lifecycle, from pregnancy through the early years of childhood. Some promising directions for community intervention design are forthcoming over the next few years, through several evaluations of a large number of communities in the United States, including the Communities Putting Prevention to Work Initiative (http://www.cdc.gov/communitiesputting preventiontowork/) as well as the Healthy Communities Study (http://www.nhlbi.nih.gov/hcs/index.htm). Continued evaluation of the EPODE International Network obesity prevention sites also should be informative (http://www.epode-interna tional-network.com/).

Although there is a large body of evidence to date on the importance of the social and environmental contexts for childhood obesity, few studies have focused on capturing the interactions between individuals and their environments. This 
is important because understanding behavioral patterns in context is critical to effective and sustainable behavioral change strategies. Advances in the application of GPS and EMA can help to fill this knowledge gap. While accelerometers brought about a breakthrough in objective measurement of physical activity, advances in accurate measurements of diet have been more difficult to develop. Improvements in data processing and technology-assisted dietary assessment have been documented in recent years [113], and we should see more testing and application of new technologies in children in the coming years.

New research on behavioral economics is expanding the array of innovative strategies to nudge children toward healthy behaviors by default. Studies reviewed included manipulating portion sizes and installing low-cost environmental cues in the food environment. Work from the Cornell Food and Brand Lab (http://foodpsychology.cornell.edu/index.html) on "smart" lunchrooms and the psychology of food marketing sheds new light on the ways humans behave - often mindlessly and not necessarily rationally. If incorporated into multilevel, multicomponent interventions across multiple settings, strategies relying on behavioral economics may render behavior change more successful and sustainable. Although behavioral economic research focuses largely on individual psychology and behavior, it is important to note that such an approach relies on environmental modifications, which may require policy action to effect.

Although we uncovered many intervention programs in this review, very little implementation and dissemination research has been conducted in this field. The importance of multisector collaboration was addressed by some papers; however, how successes can be scaled up and sustained across communities is not well understood. A recent paper offers a systems-based typology of three structural dimensions: 1) locus of interventions (top-down vs. bottom-up), 2) locus of change (policy vs. behavior), and 3) public- vs. private-sector initiative. This typology helps researchers and practitioners to consider the levers and mechanisms of change that best support the reach, scalability, and sustainability of interventions [114].

There is increasing interest in policy aspects of obesity prevention and control. Discussions of policy issues remain largely descriptive, with very few studies on policy impact. In addition, the range of policies that impact obesity is vast and the publications reviewed are limited in their coverage, focusing mainly on school policies. While policy impacts are difficult to study experimentally, evaluations of natural experiments or ecological observational studies can provide valuable information. Moreover, complex systems modeling techniques provide a unique opportunity to study policies in virtual laboratories [109]. These computational approaches allow us to construct artificial realities within which to test the effects of different policy scenarios on individual- and population-level outcomes and to anticipate any unintended consequences.

Setting common marketing standards for foods and beverages as well as implementing social marketing strategies for healthy lifestyles are strong recommendations in the Institute of Medicine's most recent report on accelerating progress in obesity prevention. Overall, very few studies to date have focused on the synergistic impact of all four Ps in marketing: product, price, placement, and promotion. In addition, current research focuses primarily on television media, but digital and electronic media are of growing importance [115]. Given the cost-effectiveness, digital media also can be used to the advantage of social marketing, strategies for which remain underdeveloped compared to the sophistication of commercial marketing.

\section{Limitations}

The search was limited to MEDLINE and only covered the period of January 2011 to May 2012, which may not include important research published in other fields, such as economics or political science. Innovations not yet published also are not included in this review. Furthermore, the information provided is not a comprehensive review of studies within each domain or theme, and subjective interpretation of innovation is inherent in such a review. However, the qualitative analysis should still provide a useful snapshot of key areas for consideration.

\section{Conclusions}

Although there is increasing pressure to solve the childhood obesity problem, the vast majority of recently published research still focuses on risk factors of obesity, whereas only one third of the research is on interventions. Among interventions, very few have incorporated community-wide, multilevel, and systems approaches, although some novel behavior change strategies are being tested. There is a great need for more solution-oriented research that combines individual, environmental, and policy strategies to address the problem comprehensively. Research will need to be increasingly transdisciplinary, incorporating methods from diverse fields to evaluate the impact of multilevel strategies working simultaneously.

Acknowledgments This work was supported in part by the Robert Wood Johnson Foundation Active Living Research Grant \#68502 and a grant from the Gretchen Swanson Center for Human Nutrition. The authors thank Jeri Brittin for assistance with artwork.

Disclosure No potential conflicts of interest relevant to this article were reported. 


\section{References}

Papers of particular interest, published recently, have been highlighted as:

•• Of major importance

1. Finucane MM, Stevens GA, Cowan MJ, et al. National, regional, and global trends in body-mass index since 1980: systematic analysis of health examination surveys and epidemiological studies with 960 country-years and $9 \cdot 1$ million participants. Lancet. 2011;377:557-67.

2. Benjamin RM. The surgeon general's vision for a healthy and fit nation. Public Health Rep. 2010;125:514.

3. Ogden CL, Carroll MD, Curtin LR, McDowell MA, Tabak CJ, Flegal KM. Prevalence of overweight and obesity in the United States, 1999-2004. JAMA. 2006;295:1549-55.

4. Ogden CL, Carroll MD, Curtin LR, Lamb MM, Flegal KM. Prevalence of high body mass index in US children and adolescents, 2007-2008. JAMA. 2010;303:242-9.

5. Singh GK, Siahpush M, Kogan MD. Rising social inequalities in US childhood obesity, 2003-2007. Ann Epidemiol. 2010;20:40-52.

6. Wang Y, Lobstein T. Worldwide trends in childhood overweight and obesity. Int J Pediatr Obes. 2006;1:11-25.

7. Swinburn BA, Sacks G, Hall KD, et al. The global obesity pandemic: shaped by global drivers and local environments. Lancet. 2011;378:804-14.

8. Gupta N, Goel K, Shah P, Misra A. Childhood obesity in developing countries: epidemiology, determinants, and prevention. Endocr Rev. 2012;33:48-70.

9. Summerbell C, Waters E, Edmunds L, Kelly S, Brown T and Campbell K. Interventions for preventing obesity in children. Cochrane Database Syst Rev. 2005;3: Art. No.: CD001871.

10. Waters E, de Silva-Sanigorski A, Hall BJ, et al. Interventions for preventing obesity in children. The Cochrane Library. 2011;12CD001871.

11. Baranowski T, Islam N, Douglass D, et al. Food intake recording software system, version 4 (FIRSSt4): a self-completed 24$\mathrm{h}$ dietary recall for children. J Hum Nutr Diet Off $\mathrm{J}$ Br Diet Assoc. 2012. doi:10.1111/j.1365-277X.2012.01251.x.

12. Biltoft-Jensen A, Trolle E, Christensen T, et al. WebDASC: a web-based dietary assessment software for 8-11-year-old Danish children. J Hum Nutr Diet Off J Br Diet Assoc. 2012. doi:10.1111/j.1365-277X.2012.01257.x.

13. Trolle E, Amiano P, Ege M, et al. Feasibility of $2 \times 24$-h dietary recalls combined with a food-recording booklet, using EPIC-Soft, among schoolchildren. Eur J Clin Nutr. 2011;65 Suppl 1:S65-76.

14. Trolle E, Amiano P, Ege M, et al. Feasibility of repeated 24h dietary recalls combined with a food-recording booklet, using EPIC-Soft, among preschoolers. Eur J Clin Nutr. 2011;65 Suppl 1: S84-6.

15. Van Cauwenberghe E, Gubbels J, De Bourdeaudhuij I, Cardon G. Feasibility and validity of accelerometer measurements to assess physical activity in toddlers. Int $\mathrm{J}$ Behav Nutr Phys Act. 2011;8:67.

16. Davies G, Reilly JJ, McGowan AJ, Dall PM, Granat MH, Paton JY. Validity, practical utility, and reliability of the activPAL in preschool children. Med Sci Sports and Exerc. 2012;44:761-8.

17. Hart TL, Brusseau T, Kulinna PH, McClain JJ, Tudor-Locke C. Evaluation of low-cost, objective instruments for assessing physical activity in 10-11-year-old children. Res Q Exerc Sport. 2011;82:600-9.

18. Colley RC, Janssen I, Tremblay MS. Daily step target to measure adherence to physical activity guidelines in children. Med Sci Sports Exerc. 2012;44:977-82.
19. Beets MW, Morgan CF, Banda JA, et al. Convergent validity of pedometer and accelerometer estimates of moderate-to-vigorous physical activity of youth. J Phys Act Heal. 2011;8 Suppl 2: S295-305.

20. Beets MW, Beighle A, Bottai M, Rooney L, Tilley F. Pedometerdetermined step-count guidelines for afterschool programs. J Phys Act Heal. 2012;9:71-7.

21. •• Oreskovic NM, Blossom J, Field AE, Chiang SR, Winickoff JP, Kleinman RE. Combining global positioning system and accelerometer data to determine the locations of physical activity in children. Geospatial Health. 2012;6:262-72. This study furthered the methodology to combine accelerometry and global positioning system (GPS) by testing several data collection methods that revealed patterns of activity mapped with location information across time.

22. •- Dunton GF, Liao Y, Intille SS, Spruijt-Metz D, Pentz M. Investigating children's physical activity and sedentary behavior using ecological momentary assessment with mobile phones. Obesity (Silver Spring Md). 2011;19:1205-12. This study validated the use of ecological momentary assessment (EMA) - mobile phone surveys for capturing real-time behavioral and contextual information - with accelerometry, and found a 4-day protocol with 3-7 surveys per day yielded valid physical activity levels.

23. Matthiessen TB, Steinberg FM, Kaiser LL. Convergent validity of a digital image-based food record to assess food group intake in youth. J Am Diet Assoc. 2011;111:756-61.

24. Brown HW, Roberts J. Exploring the factors contributing to sibling correlations in BMI: a study using the panel study of income dynamics. Obesity (Silver Spring Md). 2012;20:978-84.

25. Dubois L, Ohm Kyvik K, Girard M, et al. Genetic and environmental contributions to weight, height, and BMI from birth to 19 years of age: an international study of over 12,000 twin pairs. PLoS One. 2012;7:e30153.

26. Almanza E, Jerrett M, Dunton G, Seto E, Pentz MA. A study of community design, greenness, and physical activity in children using satellite, GPS and accelerometer data. Health Place. 2012;18:46-54.

27. Grigsby-Toussaint DS, Chi SH, Fiese BH, STRONG Kids Project Writing Group. Where they live, how they play: neighborhood greenness and outdoor physical activity among preschoolers. Int J Health Geogr. 2011;10:66.

28. Lachowycz K, Jones AP, Page AS, Wheeler BW, Cooper AR. What can global positioning systems tell us about the contribution of different types of urban greenspace to children's physical activity? Health Place. 2012;18:586-94.

29. Mecredy G, Pickett W, Janssen I. Street connectivity is negatively associated with physical activity in Canadian youth. Int J Environ Res Public Health. 2011;8:3333-50.

30. •- Stevens RB, Brown BB. Walkable new urban LEED Neighborhood-Development (LEED-ND) community design and children's physical activity: selection, environmental, or catalyst effects? Int J Behav Nutr Phys Act. 2011;8:139. This study found that children living in Leadership in Energy and Environmental Design-Neighborhood Development communities had higher levels of moderate physical activity than those in mixed and less walkable communities.

31. Dunton GF, Intille SS, Wolch J, Pentz MA. Investigating the impact of a smart growth community on the contexts of children's physical activity using ecological momentary assessment. Health Place. 2012;18:76-84.

32. Dunton GF, Liao Y, Intille S, Wolch J, Pentz MA. Physical and social contextual influences on children's leisure-time physical activity: an ecological momentary assessment study. J Phys Act Heal. 2011;8 Suppl 1:S103-8.

33. Beets MW, Banda JA, Erwin HE, Beighle A. A pictorial view of the physical activity socialization of young adolescents outside of school. Res Q Exerc Sport. 2011;82:769-78. 
34. •- Jones M, Dailami N, Weitkamp E, et al. Food sustainability education as a route to healthier eating: evaluation of a multicomponent school programme in English primary schools. Health Educ Res. 2012;27:448-58. This publication described a multicomponent program that integrated food sustainability with healthy eating, and found increased self-reported fruit and vegetable consumption as well as evidence of changes to cafeteria procurement and preparation practices.

35. Jones S, Spence M, Hardin S, Clemente N, Schoch A. Youth Can! results of a pilot trial to improve the school food environment. J Nutr Educ Behav. 2011;43:284-7.

36. Mustila T, Raitanen J, Keskinen P, Saari A, Luoto R. Lifestyle counselling targeting infant's mother during the child's first year and offspring weight development until 4 years of age: a followup study of a cluster RCT. BMJ Open. 2012;2:e000624.

37. De Coen V, De Bourdeaudhuij I, Vereecken C, et al. Effects of a 2-year healthy eating and physical activity intervention for 3-6year-olds in communities of high and low socio-economic status: the POP (Prevention of Overweight among Pre-school and school children) project. Public Health Nutr. 2012;1-9.

38. Burgi F, Niederer I, Schindler C, et al. Effect of a lifestyle intervention on adiposity and fitness in socially disadvantaged subgroups of preschoolers: a cluster-randomized trial (Ballabeina). Prev Med. 2012;54:335-40.

39. Fitzgibbon ML, Stolley MR, Schiffer LA, et al. Hip-hop to health Jr. Obesity prevention effectiveness trial: postintervention results. Obesity (Silver Spring Md). 2011;19:994-1003.

40. Puder JJ, Marques-Vidal P, Schindler C, et al. Effect of multidimensional lifestyle intervention on fitness and adiposity in predominantly migrant preschool children (Ballabeina): cluster randomised controlled trial. BMJ (Clin Res ed). 2011;343:d6195.

41. de Silva-Sanigorski A, Elea D, Bell C, et al. Obesity prevention in the family day care setting: impact of the Romp \& Chomp intervention on opportunities for children's physical activity and healthy eating. Child Care Health Dev. 2011;37:385-93.

42. Trost SG, Messner L, Fitzgerald K, Roths B. A nutrition and physical activity intervention for family child care homes. Am J Prev Med. 2011;41:392-8.

43. Witt KE, Dunn C. Increasing fruit and vegetable consumption among preschoolers: evaluation of color me healthy. J Nutr Educ Behav. 2012;44:107-13.

44. De Bock F, Breitenstein L, Fischer JE. Positive impact of a preschool-based nutritional intervention on children's fruit and vegetable intake: results of a cluster-randomized trial. Public Health Nutr. 2012;15:466-75.

45. Schultz JT, Moodie M, Mavoa H, et al. Experiences and challenges in implementing complex community-based research project: the pacific obesity prevention in communities project. Obes Rev Off J Int Assoc Study Obes. 2011;12 Suppl 2:12-9.

46. Fotu KF, Millar L, Mavoa H, et al. Outcome results for the Ma'alahi youth project, a Tongan community-based obesity prevention programme for adolescents. Obes Rev Off J Int Assoc Study Obes. 2011;12 Suppl 2:41-50.

47. Novotny R, Vijayadeva V, Ramirez V, Lee SK, Davison N, Gittelsohn J. Development and implementation of a food system intervention to prevent childhood obesity in rural Hawai'i. Hawaii Med J. 2011;70:42-6.

48. •• Borys JM, Le Bodo Y, Jebb SA, et al. EPODE approach for childhood obesity prevention: methods, progress and international development. Obes Rev Off J Int Assoc Study Obes. 2012;13:299-315. This publication describes the major components of the EPODE program in Europe, which is an example of effective social marketing utilized used at both central and local levels and integrated approach to obesity prevention. EPODE began with ten French pilot communities in 2004 and has since expanded to more than 500 communities worldwide.
49. Tripodi A, Severi S, Midili S, Corradini B. "Community projects" in Modena (Italy): promote regular physical activity and healthy nutrition habits since childhood. Int J Pediatr Obes IJPO. 2011;6 Suppl 2:54-6.

50. De Henauw S, Verbestel V, Marild S, et al. The IDEFICS community-oriented intervention programme: a new model for childhood obesity prevention in Europe? Int J Obes. 2011;35 Suppl 1:S16-23.

51. Miyoshi M, Tsuboyama-Kasaoka N, Nishi N. School-based "Shokuiku" program in Japan: application to nutrition education in Asian countries. Asia Pac J Clin Nutr. 2012;21:159-62.

52. Harnack LJ, Oakes JM, French SA, Rydell SA, Farah FM, Taylor GL. Results from an experimental trial at a head start center to evaluate two meal service approaches to increase fruit and vegetable intake of preschool aged children. Int J Behav Nutr Phys Act. 2012;9:51.

53. Bohnert AM, Randall ET, Tharp S, Germann J. The development and evaluation of a portion plate for youth: a pilot study. J Nutr Educ Behav. 2011;43:268-73.

54. Reicks M, Redden JP, Mann T, Mykerezi E, Vickers Z. Photographs in lunch tray compartments and vegetable consumption among children in elementary school cafeterias. JAMA. 2012;307:784-5.

55. Dovey TM, Taylor L, Stow R, Boyland EJ, Halford JC. Responsiveness to healthy television (TV) food advertisements/ commercials is only evident in children under the age of seven with low food neophobia. Appetite. 2011;56:440-6.

56. Roemmich JN, Lambiase MJ, McCarthy TF, Feda DM, Kozlowski KF. Autonomy supportive environments and mastery as basic factors to motivate physical activity in children: a controlled laboratory study. Int J Behav Nutr Phys Act. 2012;9:16.

57. Mitre N, Foster RC, Lanningham-Foster L, Levine JA. The energy expenditure of an activity-promoting video game compared to sedentary video games and TV watching. J Pediatr Endocrinol Metab JPEM. 2011;24:689-95.

58. Shayne RK, Fogel VA, Miltenberger RG, Koehler S. The effects of exergaming on physical activity in a third-grade physical education class. J Appl Behav Anal. 2012;45:211-5.

59. Baranowski T, Abdelsamad D, Baranowski J, et al. Impact of an active video game on healthy children's physical activity. Pediatrics. 2012;129:e636-42.

60. Owens SG, Garner JC, Loftin JM, van Blerk N, Ermin K. Changes in physical activity and fitness after 3 months of home Wii fit use. J Strength Cond Res. 2011;25:3191-7.

61. Boutelle KN, Zucker NL, Peterson CB, Rydell SA, Cafri G, Harnack L. Two novel treatments to reduce overeating in overweight children: a randomized controlled trial. J Consult Clin Psychol. 2011;79:759-71.

62. Berkowitz RI, Wadden TA, Gehrman CA, et al. Meal replacements in the treatment of adolescent obesity: a randomized controlled trial. Obesity (Silver Spring Md). 2011;19:1193-9.

63. Armeno ML, Krochik AG, Mazza CS. Evaluation of two dietary treatments in obese hyperinsulinemic adolescents. J Pediatr Endocrinol Metab. 2011;24:715-22.

64. Khadilkar VV, Pandit DS, Khadilkar AV, Chiplonkar SA, Kinare AS. Diet and exercise intervention, with special reference to micronutrients, reduces cardiometabolic risk in overweight children. Indian J Endocrinol Metab. 2012;16:124-33.

65. Maddison R, Foley L, Ni Mhurchu C, et al. Effects of active video games on body composition: a randomized controlled trial. Am J Clin Nutr. 2011;94:156-63.

66. Radon K, Furbeck B, Thomas S, Siegfried W, Nowak D, von Kries R. Feasibility of activity-promoting video games among obese adolescents and young adults in a clinical setting. J Sci Med Sport. 2011;14:42-5.

67. de Niet J, Timman R, Bauer S, et al. The effect of a short message service maintenance treatment on body mass index and 
psychological well-being in overweight and obese children: a randomized controlled trial. Pediatr Obes. 2012;7:205-19.

68. de Niet J, Timman R, Bauer S, et al. Short message service reduces dropout in childhood obesity treatment: a randomized controlled trial. Health Psychol. 2012. doi:10.1037/a0027498.

69. Wake M, Lycett K, Sabin MA, et al. A shared-care model of obesity treatment for 3-10 year old children: protocol for the HopSCOTCH randomised controlled trial. BMC Pediatr. 2012;12:39.

70. Banos RM, Cebolla A, Botella C, et al. Improving childhood obesity treatment using new technologies: the ETIOBE system. Clin Pract Epidemiol Ment Health. 2011;7:62-6.

71. Boles M, Dilley JA, Dent C, Elman MR, Duncan SC, Johnson DB. Changes in local school policies and practices in Washington State after an unfunded physical activity and nutrition mandate. Prev Chronic Dis. 2011;8:A129. http://www.cdc.gov/pcd/issues/ 2011/nov/10 0191.htm.

72. Haroun D, Wood L, Harper C, Nelson M. Nutrient-based standards for school lunches complement food-based standards and improve pupils' nutrient intake profile. $\mathrm{Br} \mathrm{J}$ Nutr. 2011;106:472-4.

73. •- Bocarro JN, Kanters MA, Cerin E, et al. School sport policy and school-based physical activity environments and their association with observed physical activity in middle school children. Health Place. 2012;18:31-8. This study explored the impact of school sports policy and found the interaction of policy and setting (i.e., sport specific, multi-purpose, open area), significantly increased boys', but not girls', activity levels, suggesting that policy mandates for environmental change was just as important as for physical education requirements.

74. Kelly B, Chapman K, King L, Hebden L. Trends in food advertising to children on free-to-air television in Australia. Aust N Z J Public Health. 2011;35:131-4.

75. Barroso CS, Rodriguez D, Camacho PL. Saturday morning television advertisements aired on English and Spanish language networks along the Texas-Mexico border. J Appl Res Child. 2011;2:17.

76. Effertz T, Wilcke AC. Do television food commercials target children in Germany? Public Health Nutr. 2011;1-8.

77. Keller SK, Schulz PJ. Distorted food pyramid in kids programmes: a content analysis of television advertising watched in Switzerland. Eur J Pub Health. 2011;21:300-5.

78. Pellai A, Vetrano S, Nobile M, Luti C. The reverse pyramid: a quali-quantitative study about food advertising inside children's television programmes. Minerva Pediatr. 2012;64:15-26.

79. Boyland EJ, Harrold JA, Kirkham TC, Halford JC. The extent of food advertising to children on UK television in 2008. Int $\mathrm{J}$ Pediatr Obes. 2011;6:455-61.

80. Huang L, Mehta K, Wong ML. Television food advertising in Singapore: the nature and extent of children's exposure. Heal Promot Int. 2012;27:187-96.

81. Hebden L, King L, Kelly B. Art of persuasion: an analysis of techniques used to market foods to children. J Paediatr Child Health. 2011;47:776-82.

82. Pettigrew S, Roberts M, Chapman K, Quester P, Miller C. The use of negative themes in television food advertising. Appetite. 2012;58:496-503

83. Prell H, Palmblad E, Lissner L, Berg CM. Health discourse in Swedish television food advertising during children's peak viewing times. Appetite. 2011;56:607-16.

84. Mehta K, Phillips C, Ward P, Coveney J, Handsley E, Carter P. Marketing foods to children through product packaging: prolific, unhealthy and misleading. Public Health Nutr. 2012;1-8.

85. Hebden L, King L, Kelly B, Chapman K, Innes-Hughes C. A menagerie of promotional characters: promoting food to children through food packaging. J Nutr Educ Behav. 2011;43:349-55.
86. •• Thomson DM. The mixed health messages of Millsberry: a critical study of online child-targeted food advergaming. Health Commun. 2011;26:323-31. This publication provided a critical analysis of an advergaming website for breakfast cereals, and found nutrition information undermined by content. The website discussed the importance of nutritional balance and caloric moderation, but included "advergames" with "spokescharacters" that have endless appetites and can eat virtual boxes of cereal in a single bite.

87. Jones SC, Gregory P, Kervin L. Branded food references in children's magazines: 'advertisements' are the tip of the iceberg. Pediatr Obes. 2012;7:220-9.

88. Potvin Kent M, Dubois L, Wanless A. A nutritional comparison of foods and beverages marketed to children in two advertising policy environments. Obesity (Silver Spring Md). 2011. doi:10.1038/oby.2011.161

89. Reeves S, Wake Y, Zick A. Nutrition labeling and portion size information on children's menus in fast-food and table-service chain restaurants in London, UK. J Nutr Educ Behav. 2011;43:543-7.

90. Tandon PS, Zhou C, Chan NL, et al. The impact of menu labeling on fast-food purchases for children and parents. Am J Prev Med. 2011;41:434-8.

91. Mellor JM. Do cigarette taxes affect children's body mass index? The effect of household environment on health. Heal Econ. 2011;20:417-31.

92. •• Nordstrom J, Thunstrom L. Economic policies for healthier food intake: the impact on different household categories. Eur J Health Econ. 2011;12:127-40. This study simulated the impact of potential tax reforms with the intent to increase fiber intake on food consumption across different household categories, and found that among seniors and families without children, reforms would lead to increases in fiber with concurrent increases in added sugar and fat intake; however, among families with children the reforms would lead to small increases in fiber with concurrent reductions in the unhealthy nutrients.

93. von Tigerstrom B, Larre T, Sauder J. Using the tax system to promote physical activity: critical analysis of Canadian initiatives. Am J Public Health. 2011;101:e10-6.

94. Cohen DA, Marsh T, Williamson S, Golinelli D, McKenzie TL. Impact and cost-effectiveness of family fitness zones: a natural experiment in urban public parks. Health Place. 2012;18:39-45.

95. Quigg R, Reeder AI, Gray A, Holt A, Waters D. The effectiveness of a community playground intervention. J Urban Health. 2012;89:171-84.

96. Henderson A, Fry CR. Better parks through law and policy: a legal analysis of authorities governing public parks and open spaces. J Phys Act Heal. 2011;8 Suppl 1:S109-15.

97. •- Lee KK. Developing and implementing the active design guidelines in New York City. Health Place. 2012;18:5-7. This publication highlights the multi-sector partnerships and complementary roles integral to the implementation of the Active Design Guidelines in New York City, which constitute an innovative set of architectural design features for buildings, streets and urban spaces that can enhance physical activity.

98. Aarts MJ, Schuit AJ, van de Goor IA, van Oers HA. Feasibility of multi-sector policy measures that create activity-friendly environments for children: results of a Delphi study. Implement Sci. 2011;6:128.

99. Aarts MJ, Jeurissen MP, van Oers HA, Schuit AJ, van de Goor IA. Multi-sector policy action to create activity-friendly environments for children: a multiple-case study. Health Policy (Amst Neth). 2011;101:11-9.

100. Olstad DL, Raine KD, McCargar LJ. Adopting and implementing nutrition guidelines in recreational facilities: public and private sector roles. A multiple case study. BMC Publ Health. 2012; $12: 376$. 
101. Lanier WA, Wagstaff RS, DeMill JH, Friedrichs MD, Metos J. Teacher awareness and implementation of food and physical activity policies in Utah elementary schools, 2010. Prev Chronic Dis. 2012;9:E18.

102. Lounsbery MAF, McKenzie TL, Trost S, Smith NJ. Facilitators and barriers to adopting evidence-based physical education in elementary schools. J Phys Act Heal. 2011;8 Suppl 1:S17-25.

103. Nathan N, Wolfenden L, Butler M, et al. Vegetable and fruit breaks in Australian primary schools: prevalence, attitudes, barriers and implementation strategies. Heal Educ Res. 2011;26:722-31.

104. Downs SM, Farmer A, Quintanilha M, et al. From paper to practice: barriers to adopting nutrition guidelines in schools. $\mathrm{J}$ Nutr Educ Behav. 2012;44:114-22.

105. •• Andreyeva T, Middleton AE, Long MW, Luedicke J, Schwartz MB. Food retailer practices, attitudes and beliefs about the supply of healthy foods. Public Health Nutr. 2011;14:1024-31. This study assessed food retailers' attitudes and perceptions regarding healthy food provision. Food retailers noted that stocking decisions were driven by customer demand, which they perceived as low for healthy food items. Further, this study revealed that food producer and supplier networks varied across stores, but the least healthy foods were most likely to be direct-store delivery providing convenient direct shelving of products, whereas healthier foods were more likely to be either self-supply or general delivery.

106. Barnes M. Solving the problem of childhood obesity within a generation. White house task force on childhood obesity, May 2010. Available: http://www.letsmove.gov/pdf/TaskForce_on Childhood_Obesity_May2010_FullReport.pdf.

107. UN General Assembly (2011) Political declaration of the highlevel meeting of the general assembly on the prevention and control of non-communicable diseases (NCDs). New York: UN. Available: http://www.un.org/en/ga/ncdmeeting2011/.

108. Huang TT, Drewnowski A, Kumanyika SK, Glass TA. A systems-oriented multilevel framework for addressing obesity in the 21st century. Prev Chronic Dis. 2009;6:A82. http:// www.cdc.gov/pcd/issues/2009/jul/09_0013.htm.

109. Hammond RA. Peer reviewed: complex systems modeling for obesity research. Prev Chronic Dis. 2009;6:A97. http:// www.cdc.gov/pcd/issues/2009/jul/09_0017.htm.

110. Institute of Medicine (IOM). Accelerating progress in obesity prevention: Solving the weight of the nation. Washington, DC: The National Academies Press; 2012.

111. Mabry PL, Olster DH, Morgan GD, Abrams DB. Interdisciplinarity and systems science to improve population health: a view from the NIH Office of Behavioral and Social Sciences Research. Am J Prev Med. 2008;35:S211-24.

112. Nader PR, Huang TTK, Gahagan S, Kumanyika S, Hammond RA and Christoffel KK. Next steps in obesity prevention: altering early life systems to support healthy parents, infants, and toddlers. Child Obes (Formerly Obesity Weight Manag). 2012;195-204.

113. Thompson FE, Subar AF, Loria CM, Reedy JL, Baranowski T. Need for technological innovation in dietary assessment. J Am Diet Assoc. 2010;110:48.

114. Huang TTK, Grimm B, Hammond RA. A systems-based typological framework for understanding the sustainability, scalability, and reach of childhood obesity interventions. Child Health Care. 2011;40:253-66.

115. Lenhart A. Social media \& mobile internet use among teens and young adults. Pew Internet \& American Life Project. 2010. 